\title{
Nanoparticle-allergen interactions mediate human allergic responses: protein corona characterization and cellular responses
}

\author{
Isabella Radauer-Preiml' ${ }^{1}$, Ancuela Andosch², Thomas Hawranek ${ }^{3}$, Ursula Luetz-Meindl2 ${ }^{2}$ Markus Wiederstein ${ }^{4}$,
} Jutta Horejs-Hoeck ${ }^{1}$, Martin Himly ${ }^{1}$, Matthew Boyles ${ }^{5}$ and Albert Duschl ${ }^{1^{*}}$

\begin{abstract}
Background: Engineered nanomaterials (ENMs) interact with different biomolecules as soon as they are in contact, resulting in the formation of a biomolecule 'corona'. Hence, the 'corona' defines the biological identity of the ENMs and could affect the response of the immune system to ENM exposure. With up to $40 \%$ of the world population suffering from type I allergy, a possible modulation of allergen effects by binding to ENMs is highly relevant with respect to work place and consumer safety. Therefore, the aim of this present study was to gain an insight into the interactions of gold nanoparticles with different seasonally and perennially occurring outdoor and indoor allergens.

Methods: Gold nanoparticles (AuNPs) were conjugated with the major allergens of birch pollen (Bet $\vee 1$ ), timothy grass pollen (Phl p 5) and house dust mite (Der p 1). The AuNP-allergen conjugates were characterized by means of TEM negative staining, dynamic light scattering (DLS), z-potential measurements and hyperspectral imaging.

Furthermore, 3D models were constructed, based on the characterization data, to visualize the interaction between the allergens and the AuNPs surface. Differences in the activation of human basophil cells derived from birch/grass pollen- and house dust mite-allergic patients in response to free allergen and AuNP-allergen conjugates were determined using the basophil activation assay (BAT). Potential allergen corona replacement during BAT was controlled for using Western blotting. The protease activity of AuNP-Der $p 1$ conjugates compared to free Der $p 1$ was assessed, by an enzymatic activity assay and a cellular assay pertaining to lung type II alveolar epithelial cell tight junction integrity.

Results: The formation of a stable corona was found for all three allergens used. Our data suggest, that depending on the allergen, different effects are observed after binding to ENMs, including enhanced allergic responses against Der $p 1$ and also, for some patients, against Bet $\vee 1$. Moreover elevated protease activity of AuNP-Der p 1 conjugates compared to free Der $\mathrm{p} 1$ was found.
\end{abstract}

Conclusion: In summary, this study presents that conjugation of allergens to ENMs can modulate the human allergic response, and that protease activity can be increased.

Keywords: Gold nanoparticles, Protein corona, Allergy, Basophil activation, Protease activity, A549 cells

\footnotetext{
* Correspondence: albert.duschl@sbg.ac.at

'Department of Molecular Biology, Division of Allergy and Immunology,

University of Salzburg, Hellbrunnerstr, 34, 5020 Salzburg, Austria

Full list of author information is available at the end of the article
} 


\section{Background}

With the increasing use of ENMs concerns about the safety upon exposure of workers, consumers and the environment were raised [1-3]. One crucial feature of ENMs is that they possess a higher free energy than the bulk material, which means that the ENMs surface will interact with different biomolecules as soon as they are in contact, resulting in the formation of a 'corona' around the ENMs [4]. The biomolecule corona changes the extrinsic properties of the ENMs, but also structures and functions of the biomolecules themselves may be modified upon binding. Thus, if the corona consists of an allergen the overall bio-reactivity of the ENM/corona complex may have the potential to elicit or modulate an allergic response [5-8].

As the overall size of the ENMs would increase only marginally by allergen binding, the ENMs-allergen conjugates could still be inhaled and could translocate from the lung into the bloodstream. Contact with epithelial and/or immune cells and in particular uptake into these cells may result in immune responses [9, 10]. Type I allergy, affecting 30-40\% of the population worldwide, is characterized by the production of immunoglobulin $\mathrm{E}$ (IgE) antibodies against allergens. IgE-mediated allergic rhinitis is a risk factor for asthma, a life-long chronic inflammatory disease of the airways, which seriously impacts quality of life and can, when uncontrolled, lead to death [11]. Upon allergic sensitization in the human airways, epithelial cells encountering allergens can release thymic stromal lymphopoietin (TSLP) to attract, activate and polarize dendritic cells (DCs). Activated DCs migrate to lymph nodes, expressing the CC-chemokine ligands (CCL) 17 and CCL22 for T cell attraction [12-14]. In the lymph node, DCs present processed antigens to $\mathrm{T}$ cells, and by several mechanisms initiate an immune deviation into a $\mathrm{T}$ helper cell $2\left(\mathrm{~T}_{\mathrm{H}} 2\right)$-type profile characterized by secretion of interleukin (IL)-4, IL-5 and IL-13. The $\mathrm{T}_{\mathrm{H}} 2$ cells induce a class-switch in $\mathrm{B}$ cells resulting in the production of allergen-specific IgE $[15,16]$. During the acute phase of allergy (effector phase), IgE molecules on mast cells and basophils crosslink the cells' high affinity IgE receptors, initiating a signaling cascade that leads to the release of preformed mediators, enzymes and cytokines, resulting in pathological damage and clinical manifestation of allergy [17-19]. Allergic symptoms can occur seasonally, e.g. after exposure to pollen, or perennially during the exposure to indoor allergens [20]. In Europe the most allergenic tree pollen is produced by birch (major allergen Bet $\mathrm{v} 1$ ). Pollinosis is also caused by grass pollen, a well-known example being timothy grass (major allergens $\mathrm{Phl} \mathrm{p} 1$ and 5) [21]. House dust mite, found in $48 \%$ of European homes, represents the major perennial indoor allergen source (major allergens Der p 1 and 2) [22, 23]. Research on co-exposure to allergens and particles has initially focused on diesel exhaust particles (DEPs). It was shown in previous studies that DEPs can bind Lol p 1, a major grass pollen allergen, and that DEPs can increase the production of allergen-specific IgE in Epstein-Barr virus (EBV)-transformed human B-lymphocytes when exposed to different polycyclic aromatic hydrocarbons (PAHs), a main component found in DEPs [24, 25]. When DEPs and different allergens were administered simultaneously, higher specific IgE levels were found in human nasal lavages as well as in blood drawn from mice [24, 26, 27]. Much less is known about effects of co-exposure of allergens with ENMs. Numerous studies have explored options to employ ENMs as carriers in immunotherapy against allergies [28-32], but the possible risk of unintentional coexposure has been less explored. The studies performed so far have mainly focused on various established mouse models [33-39].

Furthermore, upon release of ENMs into the environment, which can occur by accident but also upon disposal or via abrasion, ENMs can interact with different allergens. Therefore, this study aimed to determine effects of allergens present as corona compounds on ENMs on the allergic response of human cells, focusing on basophils and on alveolar epithelial cells. Bet v 1 for tree and Phl p 5 for grass pollen, both representing outdoor allergens, and Der p 1, the major allergen for house dust mite, representing indoor allergens were selected. The binding of allergens onto AuNPs and investigated differences in the allergic response of free compared to conjugated allergens was determined. AuNPs were chosen as model ENMs as their reactivity is low, allowing well controlled characterization, and they do not cause an allergic response on their own, enabling an investigation solely on modulation of allergen-specific responses upon particle binding. Furthermore, the behavior of these ENM-allergen conjugates may provide insights into the use of AuNPs as candidates in nanotherapeutic applications. Additionally, as the enzymatic function of Der p 1 as a cysteine protease is considered to play a role in the allergic sensitization, we also investigated the influence of the AuNP-allergen interaction on proteolytic activity of Der p $1[12,40]$.

\section{Methods}

\section{AuNP-allergen conjugates}

AuNPs $\left(3.5^{*} 10^{10} \mathrm{NPs} / \mathrm{ml}, 50 \mathrm{~nm}\right.$, stabilized in $0.1 \mathrm{mM}$ phosphate buffered-saline (PBS), Sigma-Aldrich, St. Louis, MO, USA) were incubated with different concentrations of purified recombinant allergens, i.e. $2.5 \mu \mathrm{g}$ Bet $\mathrm{v} 1$ (courtesy of C. Ackaert as described in 2014 [41]), $5 \mu \mathrm{g}$ Der p 1 (Indoor Biotechnologies INC., Cardiff, United Kingdom) or $3 \mu \mathrm{g}$ Phl p 5 (Allergopharma GmbH, Reinbek, Germany) as described by O. Cromwell et al. [42], on a test tube rotator (Snijders, Tilburg, Netherlands) 
at $4{ }^{\circ} \mathrm{C}$ overnight. The excess protein was removed by performing three washing steps of 5 min centrifugation at $18,000 \mathrm{rpm}$ followed by resuspension in the original buffer.

\section{Characterization of AuNPs, AuNP-allergen conjugates and allergens}

AuNPs were characterized by TEM. The protein corona of AuNP-allergen conjugates was also characterized by TEM with protein negative staining. For these investigations samples were taken directly after the conjugation, before the removal of unbound proteins, and were incubated with $1 \%$ uranyl acetate on coated copper grids to stain the proteins. Images were taken using a LEO 912 AB Omega transmission electron microscope (Carl Zeiss, Oberkochen, Germany) operated with a LaB6 cathode at a voltage of $120 \mathrm{kV}$. Images were filtered at zero energy loss.

The hydrodynamic radius and surface charge of AuNPs and AuNP-allergen conjugates were determined using a Malvern ZetaSizer Nano ZSP (Malvern Instruments, Malvern, UK). The assessment of the molecular size and potential protein aggregation of the free allergens was performed on the DLS802 (Viscotek, Houston, TX, USA) as previously described by Himly et al. [43].

For further confirmation of hard corona formation, optical and hyperspectral imaging analysis were conducted on a darkfield-based optical illumination system from CytoViva (CytoViva Inc., Auburn, AL, USA). AuNPs and AuNP-allergen conjugates were applied to a microscope slide and covered with a cover glass (both Carl Roth GmbH CoKG, Karlsruhe Germany). The principle of the measurement is based upon the characteristic scattering profile of AuNPs. Each pixel of the image was recorded at a wavelength of $400-1000 \mathrm{~nm}$, and was automatically compared by the classification algorithm spectral angle mapper (SAM) to the AuNPallergen conjugates. The data is presented as normalized mean regions of interest (ROI's) of 1100 AuNP-allergen conjugates normalized to the mean ROI of 1100 AuNPs.

\section{Quantification of the bound allergen}

Reversed phase - high performance liquid chromatography (RP-HPLC) was performed to determine the free allergen concentrations before and after the conjugation. Indirect quantification of AuNP-bound allergen was achieved by comparing the obtained peak areas of the UV absorption signals at $214 \mathrm{~nm}$ of the original free allergen suspension with the signal obtained from supernatants collected after conjugation with AuNPs, after the above-mentioned washing steps. The measurements were carried out on an UltiMate 3000 system (ThermoFisher Scientific Inc., Palo Alto, CA, USA) using a C18 Acclaim $^{\mathrm{TM}} 300$ column $(2.1 \times 150 \mathrm{~mm}, 3 \mu \mathrm{m}$, ThermoFisher) at a flow rate of $500 \mu \mathrm{l} / \mathrm{min}$ and a column temperature of $50{ }^{\circ} \mathrm{C}$. The gradient of the solvents $\mathrm{A}$
$\left(\mathrm{H}_{2} \mathrm{O}+0.1 \%\right.$ trifluoroacetic acid (TFA)) and B (acetonitrile $(\mathrm{ACN})+0.1 \%$ TFA, both Sigma-Aldrich) was programmed in the following way: 10-60\% solvent A $10 \mathrm{~min}, 80 \%$ solvent A $5 \mathrm{~min}, 10 \%$ solvent A $10 \mathrm{~min}$. A full loop injection of $20 \mu \mathrm{l}$ with a loop volume of $100 \mu \mathrm{l}$ was used.

\section{D model of AuNP-allergen conjugates}

Molecular graphics and analyses were performed with the UCSF Chimera package [44]. Atomic coordinates of allergens were obtained from experimentally determined structures of Bet v 1 (PDB code: 4a88, chain A), Der p 1 (PDB code: $3 f 5 v$, chain A) and Phl p 5 (PDB code: $2 \mathrm{~m} 64$, chain A, NMR model 1) $[45,46]$. All three allergens were visualized in a monomeric state and positioned randomly on the surface of an idealized AuNP represented by a sphere of $51 \mathrm{~nm}$ diameter, approximately corresponding to the nanoparticle size determined by DLS (see Table 1). Having to decide for plausible orientations of the protein molecules on the AuNP surface, we followed the rationale that the negative potential of a citrate-coated gold surface may select orientations of the protein molecules where positively charged surface patches face the AuNP surface. In order to identify such patches, charges and atom radii were assigned to protein atoms using PDB2PQR $[47,48]$ and the PARSE parameter set [49]. Subsequently, electrostatic potentials were calculated with the APBS software package [50] $(129 \times 129 \times 129$ grid points, solute dielectric constant $=2.0$, solvent dielectric constant $=78.54$, solvent radius $=1.4$ Angstrom) . The following coarse-grained docking procedure was applied to find electrostatically preferred orientations of a protein molecule relative to the AuNP: for all possible $1 \times 12 \times 12=1728$ combinations of $30^{\circ}$-rotations about three orthogonal axes centered at the molecule, we minimized the distance of the rotated allergen to the AuNP (distance cutoff $=5$ Angstrom) and then summed up the electrostatic potential values at all grid points located at the AuNP surface. Orientations were ranked by this sum and top-ranking solutions (i.e. those with the most positive sum) were chosen for visualization.

\section{Basophil activation test}

Whole blood of nine patients allergic to Bet $\mathrm{v} 1$, five patients allergic to Der p 1 and six patients allergic to Phl p 5, displaying rhinitis and conjunctivitis symptoms, diagnosed at the allergy clinic of the Paracelsus Medical University of Salzburg were studied. The study was approved by the local ethics committee and all patients participating gave their written informed consent. Basophil activation was performed from Ethylene diamine tetraacetic acid (EDTA)-whole blood using Flow CAST (Buehlmann Laboratories, Schoenenbuch, Switzerland) according to the manufacturer's protocol. Whole blood 
Table 1 Size distribution, PDI and zeta potential measurements of AuNPs, allergens and AuNP-allergen conjugates

\begin{tabular}{llllll}
\hline Sample & Average Diameter $(\mathrm{nm})$ & Pdl & Difference from AuNPs $(\mathrm{nm})$ & Zeta Potential $(\mathrm{mV})$ & Difference from AuNPs $(\mathrm{mV})$ \\
\hline Au NPs & $50.9 \pm 0.6$ & \pm 0.010 & --- & $-42.2 \pm 2.2$ & --- \\
Bet v 1 & $3.92 \pm 0.6$ & -- & --- & --- & --- \\
Der p 1 & $4.94 \pm 2.4$ & --- & --- & --- & --- \\
Phl p 5 & $6.48 \pm 0.6$ & -- & --- & --- & $3 \pm 1.7$ \\
AuNP-Bet v 1 & $53.1 \pm 1.3$ & $0.101 \pm 0.020$ & $2.2 \pm 0.7$ & $-39.2 \pm 0.5$ & $12.6 \pm 1.1$ \\
AuNP-Der p 1 & $54.2 \pm 2.8$ & $0.141 \pm 0.010$ & $3.3 \pm 2.2$ & $-29.6 \pm 1.1$ & $8 \pm 1.3$ \\
AuNP-Phl p 5 & $54.6 \pm 1.7$ & $0.103 \pm 0.016$ & $3.6 \pm 1.1$ & $-34.2 \pm 0.9$ & \\
\hline
\end{tabular}

samples were stimulated with different concentrations of allergen or AuNP-allergen conjugates (Bet $\mathrm{v} 1$ : 50 $0.048 \mathrm{ng}$, Der p 1: 50 - 0.04 ng, Phl p 5: $50-0.078 \mathrm{ng}$ ), and the corresponding amounts of free allergen were included as controls. Processed samples were analyzed by flow cytometry (FACSCanto ${ }^{\mathrm{TM}}$ II, BD Bioscience, San Jose, CA, USA) using FACSDiva 5.02. Basophils were gated as side scatter $(\mathrm{SSC})^{\text {low }} / \mathrm{C}$-C chemokine receptor 3 $(\mathrm{CCR} 3)^{\text {high }}$ and activated basophils were identified as Cluster of differentiation (CD) $63^{\text {high }}$ when cut-off was set with the negative stimulation control. CD63 upregulation was assessed in a minimum of 500 basophils per assay. C50 values (i.e. allergen concentration inducing half-maximal basophil activation) for the AuNP-allergen conjugates were determined by logarithmic approximation (certainty $\mathrm{R}^{2}>0.900$ ) in comparison to the allergen alone.

\section{Enzymatic activity assay}

Different concentrations of free Der p 1 (50 and 100 ng) and $30 \mathrm{ng}$ AuNP-Der p 1 conjugates were incubated with $1 \mathrm{mM}$ dithiothreitol (DTT), as reducing agent to activate the cysteine protease, for $10 \mathrm{~min}$ at $37{ }^{\circ} \mathrm{C}$. For conjugates the given value refers to the amount of conjugated allergen. After incubation the assay was conducted in $50 \mathrm{mM}$ sodium phosphate buffer, $\mathrm{pH}$ 7.0, with $100 \mu \mathrm{M}$ Boc-Gln-Ala-Arg-AMC (PeptaNova GmbH, Sandhausen, Germany) as substrate according to the manufacturer's protocol. The fluorescence intensity was recorded at ex/em 380/460 $\mathrm{nm}$ using a M200Pro plate reader (Tecan, Groedig, Austria) for $20 \mathrm{~min}$.

\section{Permeability assay and TEER measurements}

The human lung alveolar adenocarcinoma cell line A549 (ATCC, Manassas, USA) was cultured in RPMI 1640 medium (Sigma-Aldrich), supplemented with $10 \%$ fetal calf serum (FCS; PAA, Pasching, Austria), $100 \mathrm{U} / \mathrm{ml}$ Penicillin, $100 \mu \mathrm{g} / \mathrm{ml}$ Streptomycin, $2 \mathrm{mM}$ L-glutamine (Sigma-Aldrich). The cells were seeded in 24-well inserts (high pore density, $0.33 \mathrm{~cm}^{2}$ growth area, $0.4 \mu \mathrm{m}$ PET, Merck-Millipore KGaA, Darmstadt, Germany) at a density of $1.5 \times 10^{5}$ cells $/ \mathrm{ml}$. Transepithelial electrical resistance (TEER) measurements were performed using a
TEER electrode (WPI, Sarasotay, USA) to monitor the cell growth every $24 \mathrm{~h}$. Therefore, the medium was changed and the electrode was washed with RPMI medium between measurements. The TEER values were calculated for the dimension $\left[\mathrm{Ohm} * \mathrm{~cm}^{2}\right]$ by subtracting the medium only control from the obtained values followed by multiplication with the surface area of the insert. As soon as no further increase in TEER values could be observed, the medium was changed to growth medium without FCS and cells were exposed to $2.5 \mathrm{mM}$ EDTA as a positive control, $0.01 \mathrm{mM}$ DTT, $3.5 \times 10^{10}$ AuNPs, $530 \mathrm{ng}$ free Der p 1, and $3.5 \times 10^{10}$ AuNP-Der $\mathrm{p}$ 1 conjugates for $24 \mathrm{~h}$. Thereafter, the medium was changed, and TEER measurements were performed as previously described. For determination of the epithelium permeability A549 cells were incubated with $2.5 \mu \mathrm{g}$ /insert of Fluorescein (Sigma-Aldrich) at $37{ }^{\circ} \mathrm{C}$ for $1 \mathrm{~h}$. To assess the percentage of permeated Fluorescein, $100 \mu \mathrm{l}$ of the lower compartment was transferred into black culture plates (Greiner Bio-One $\mathrm{GmbH}$, Kremsmuenster, Austria) and the fluorescence at ex/em 485/515 nm was measured using a plate reader (Tecan).

\section{Statistical analysis}

For TEER measurements and permeability experiments, results are expressed as mean value \pm standard deviation (SD) of 3 independent experiments; calculated using Microsoft Office Excel 2007. Statistical analysis was performed using Student's t-test in GraphPad Prism 5. Due to the donor-to-donor variations expected and observed in the BAT measurements, no statistical analysis was performed for these experiments.

\section{Results and discussion}

Preparation and characterization of AuNPs and AuNP-allergen conjugates

Allergen conjugation was performed using commercially available citrate-stabilized $50 \mathrm{~nm}$ AuNPs (Sigma-Aldrich), and characterized using TEM, DLS, and zeta potential determination. AuNPs were determined to have a negative zeta potential, which was due to the citrate coating to prevent AuNP aggregation (Table 1), and 
as depicted in Fig. 1a the TEM images show monodispersed AuNPs of approximately $50 \mathrm{~nm}$, confirmed in DLS measurements with a low polydispersity index (PdI) (Fig. 1b). In order to allow the formation of a stable corona, the AuNPs were conjugated overnight with highly purified recombinant allergens, either Bet v 1, Der p 1 or Phl p 5, and the resulting AuNP-allergen conjugates were separated from the excess allergens by a series of centrifugation and washing steps. After the conjugation the presence of an intact protein corona on the AuNP-allergen conjugates was verified using TEM with negative staining (Fig. 1a), DLS (Fig. 1b), zeta potential measurements (Table 1), hyperspectral imaging (Fig. 1c) and RP-HPLC (Fig. 1d).

The TEM negative staining visualized the bound allergen corona as a light halo around the AuNPs on a dark protein background, which was found for all three AuNPallergen conjugates. Additionally, optical and hyperspectral imaging of the AuNPs and AuNP-allergen conjugates were performed using the system of Cytoviva. A clear shift in wavelength upon allergen binding to AuNPs was found for all three AuNP-allergen conjugates. Results from all

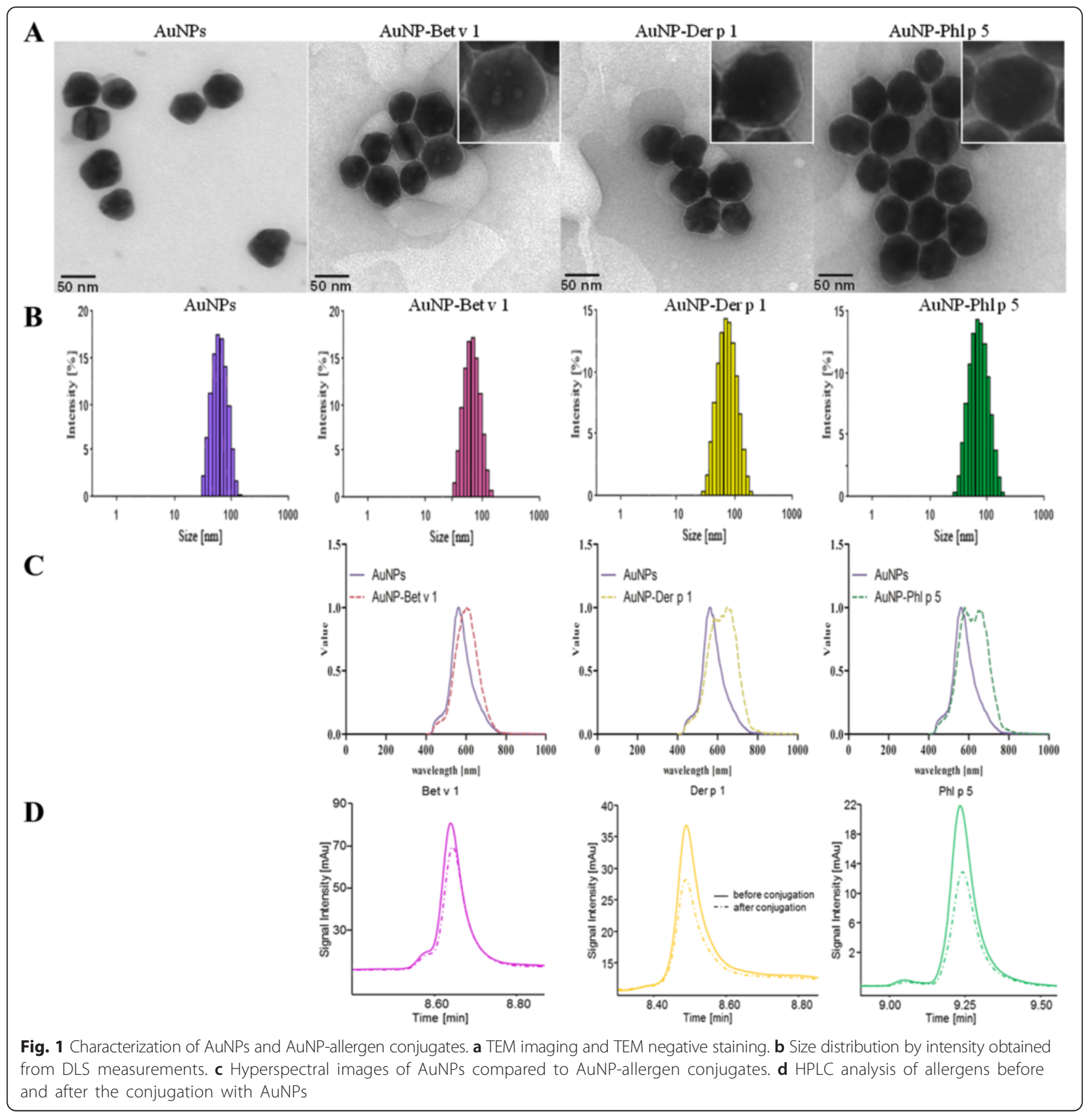


methods used for characterization corresponded well and demonstrated that the allergens were successfully conjugated to the AuNPs. Accordingly, the DLS measurements indicated a size increase and zeta potential experiments determined a marked drop in the negative values when comparing AuNP-allergen conjugates to the AuNPs alone. The obtained size increase of the AuNP-allergen conjugates did not correlate with the measured hydrodynamic radius of the allergens, which is due to the fact that DLS gives the hydrodynamic radius of a perfectly shaped sphere, which may often lead to an underestimation of the actual size [51]. Moreover, when investigating the shape of the allergens from their crystal structures as described by de Halleux et al. [52] and Kofler et al. [46] it can be seen that the allergens are not spherical, but rather adopt a cylindrical shape. For quantification of bound allergen we first employed a theoretical determination. For such estimations the equation previously published by Dell'Ocro et al. [53] was used. Therefore, the obtained hydrodynamic radii of the AuNP-allergen conjugates were divided by the hemispheres of the allergens resulting in the maximal numbers of binding sites available for each allergen on the AuNP surface. These calculations showed that DLS data can be used to determine the available binding sites of allergens on the AuNPs surface (Table 2). In order to address this issue experimentally, an indirect quantification using RP-HPLC was conducted (Fig. 1d). Single peaks were detected for the corresponding allergens, which eluted at $8.6 \mathrm{~min}$ (Bet v 1), $8.4 \mathrm{~min}$ (Der p 1), and $9.2 \mathrm{~min}$ (Phl p 5), respectively. The peak areas of allergens before and after the conjugation were compared and the respective allergen concentrations as well as the number of allergen molecules bound to the AuNPs were calculated for each preparation (Table 2). It is noteworthy that the results obtained from both methods matched well, however, for all further experiments the values obtained by the RP-HPLCbased indirect quantification method was used [54].

For further characterization of binding properties we assessed arrangement and orientation, and more specifically the conjugation degree, of the three AuNP-allergen conjugates $[55,56]$. Based on the HPLC results we computed 3D models of AuNP-allergen conjugates (Fig. 2). Approximate numbers of allergen molecules per AuNP were adopted from HPLC experiments (Table 2) and set to 510 (Bet v 1), 380 (Der p 1) and 140 (Phl p 5), illustrating the amount of AuNP surface covered by allergen
(Fig. 2a). Figure 2b shows two possible orientations of the three allergens on the AuNP surface. It was assumed that the orientation selection of allergen molecules relative to the citrate-coated AuNP surface is primarily controlled by long-range electrostatic interactions $[55,57,58]$. Therefore, the chosen orientations minimize contacts between negative charges and mainly place positively charged allergen residues on the AuNP surface. In Fig. 2c, these orientations are shown with accessible allergen epitopes highlighted in orange. In all three allergens used the epitopes are available for recognition via IgE.

\section{Impact of the conjugation to AuNPs on the effector function of allergens}

After using various methods for protein corona characterization, we were confident that AuNP-allergen conjugates had been formed. Other methods are available, such as nuclear magnetic resonance, infrared spectroscopy or circular dichroism, which provide an indication of structural conformation [56]. The structural integrity of the allergens used in this study when bound to AuNPs is important since structural changes can modulate the biological response. However, the use of these methods by Calzolai et al. [56] require $>400$-fold more protein than we used in our study, making these methods impossible to use in our experimental conditions. Furthermore, we consider that allergen-specific cellular responses are mainly driven by the availability and accessibility of intact epitopes, which are not limited to a particular tertiary structure or orientation of the allergen. Therefore, we performed the BAT, as its clinical relevance as a highly specific in vitro test system for allergenic activity was just recently emphasized by a position paper of the European Academy for Allergy and Clinical Immunology by Hoffmann et al., in 2015 including the use of BAT to monitor the patient's sensitivity to inhalant allergens over time [59]. The aim was to provide not only an indication of available epitopes, but also to determine if the binding of allergens to AuNPs can heighten or reduce an allergic reaction. This test gives a direct assessment of allergenic effects in sensitized humans. Although human basophils are the least abundant population of granulocytes, they play a crucial role in the immediate-type allergic reaction and moreover in allergic inflammation in general $[17,60,61]$. The exposure of basophils, from sensitized subjects, to allergens induces cross-linking

Table 2 DLS and RP-HPLC measurements to determine the amount of conjugated allergen

\begin{tabular}{lcccc}
\hline Sample & $\begin{array}{c}\text { Calculated concentration } \\
\text { from DLS (ng/ml) }\end{array}$ & $\begin{array}{l}\text { Allergen molecules/AuNP } \\
\text { determined by DLS }\end{array}$ & $\begin{array}{l}\text { HPLC determined } \\
\text { concentration (ng/ml) }\end{array}$ & $\begin{array}{l}\text { Allergen molecules/AuNP } \\
\text { determined by HPLC }\end{array}$ \\
\hline AuNP-Bet v 1 conjugates & $657 \pm 13.3$ & $648 \pm 16$ & $490 \pm 68.3$ & $516 \pm 77$ \\
AuNP-Der p 1 conjugates & $578 \pm 11.7$ & $415 \pm 10$ & $530 \pm 3.78$ & $379 \pm 2$ \\
AuNP-Phl p 5 conjugates & $365 \pm 7.4$ & $224 \pm 5$ & $250 \pm 24.2$ & $138 \pm 13$ \\
\hline
\end{tabular}




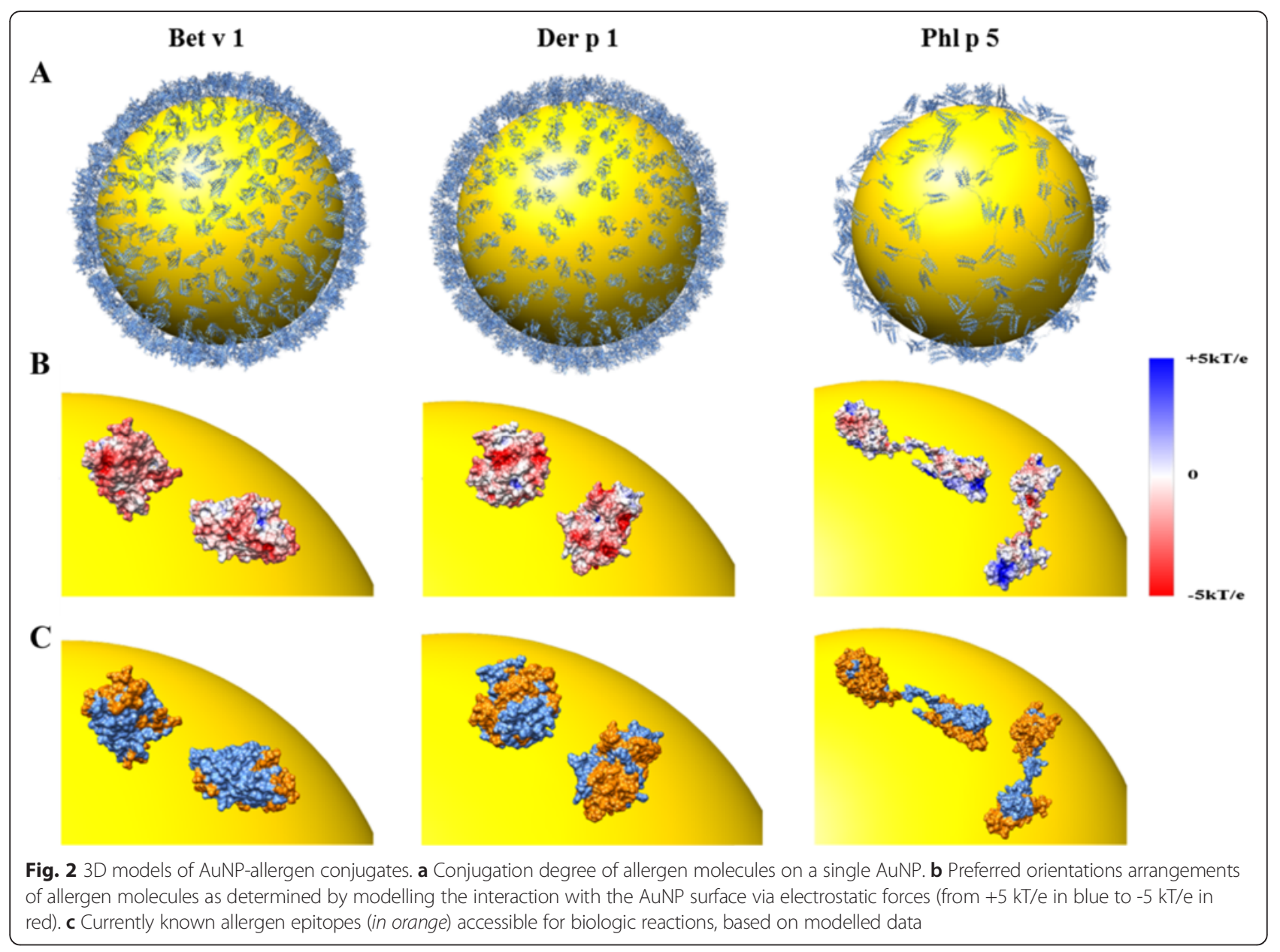

of the allergen-specific IgE bound to the cell surface via its high affinity receptor for IgE (FceRI), facilitated by the presence of multiple non-overlapping IgE-binding epitopes, resulting in cell degranulation with the release of preformed mediator substances including histamine, leukotrienes, prostaglandins, and proteases. Upon degranulation, the basophil activation marker CD63, which in resting basophils is located only in the membrane of the granules, is expressed at the surface of the basophils, and this correlates with the released histamine concentration [62-64]. Donor-to-donor variations can occur, as not only the amount of allergen-specific $\mathrm{IgE}$ in the serum and the number of FceRI can vary, but also the IgE repertoire can be different between different patients. This is expected for a natural polyclonal IgE response, as for a number of major allergens a distribution of IgE epitopes across the entire surface has been shown $[62,65,66]$. Accordingly, a number of conformational, i.e. discontinuous IgE epitopes of Bet v 1, Der p 1 and Phl p 5 have been identified by $\mathrm{mAB}$-based, epitope grafting, site-directed mutagenesis, X-ray crystallography and mimotope approaches [45, 65, 67-73]. Our 3D model of AuNP-allergen conjugates hypothesizes coupling of the allergens to the citrate-coated AuNP surface based on electrostatic interaction, which may, in the case of certain examples of positively charged interaction patches, result in an alignment on the AuNP surface where the allergens repetitively display the same epitopes. To investigate integrity and accessibility of IgE epitopes, experiments were performed using allergic patients' whole blood and stimulation of the basophils with the allergen, the AuNP-allergen conjugates and the plain AuNPs. No basophil activation was found when exposed to the AuNPs alone. The assay was performed for nine donors allergic to Bet v 1 , five donors allergic to Der $\mathrm{p} 1$, and eight donors allergic to Phl p 5. All donors tested could be divided into three categories:

i. Donors that did not display a difference in basophil activation when comparing free versus AuNP-allergen conjugates, as similar $\mathrm{C} 50$ values were observed. These included examples from each patient subset, with two, and three examples for Bet $\mathrm{v} 1$ and Phl p 5, respectively (Figs. 3, 4, 5, Table 3). This infers that in these donors the allergen-specific IgE antibodies recognized the same epitopes irrespective of 


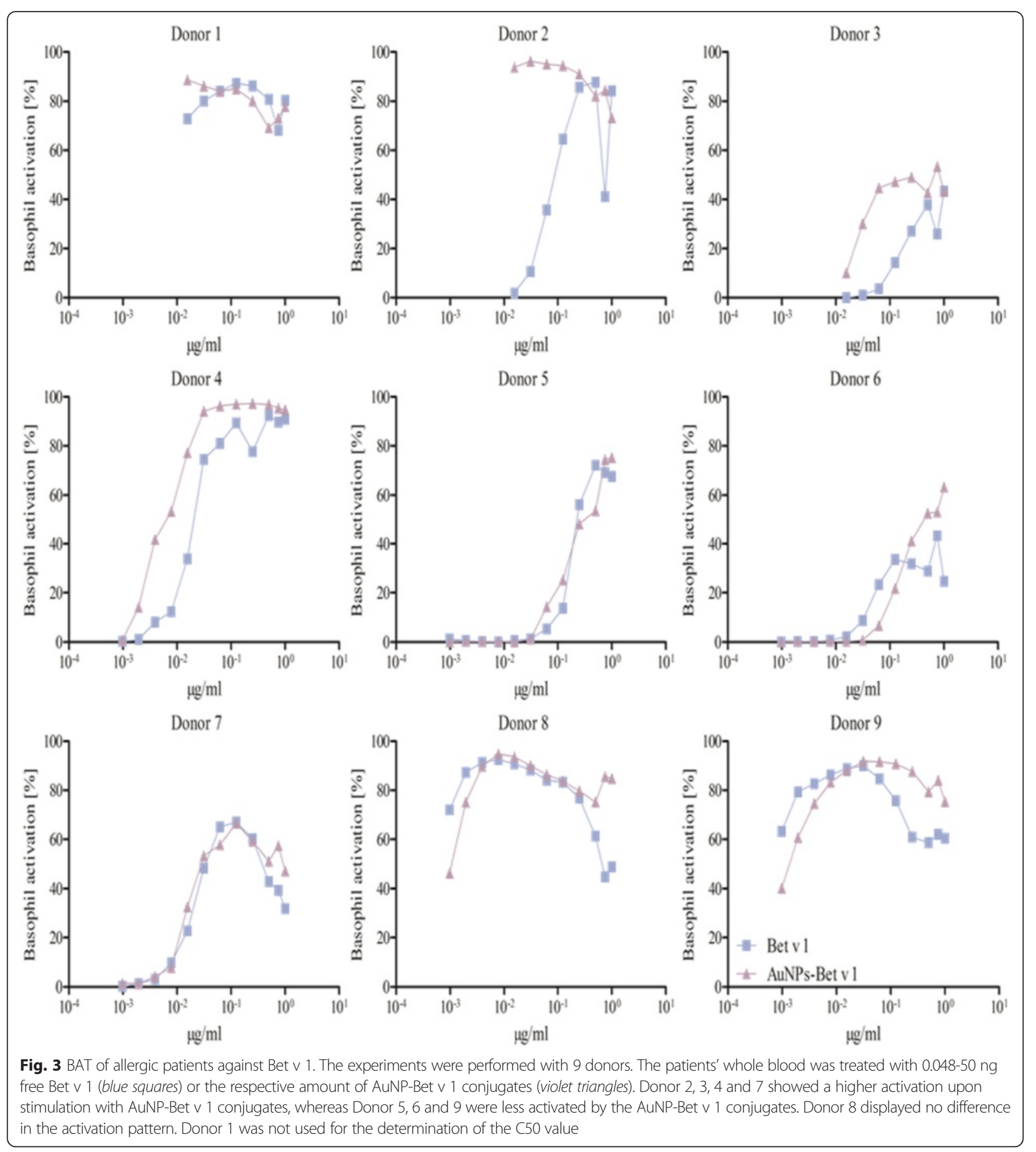

whether the allergens were free or conjugated to the AuNPs.

ii. Donors with lower basophil activation and higher C50 values upon stimulation with AuNP-allergen conjugates compared to free allergen, as shown for Bet v 1 and Phl p 5, with three and one examples, respectively (Figs. 3, 5, Table 3). In the case of Der p 1, no reduction in basophil activation was found when allergen was bound to the AuNPs. This observation may be explained by an allergen arrangement on the AuNPs surface, where epitopes are partially hidden or that these patients' do not display the specific $\operatorname{IgE}$ against this epitope [62, 74].

iii. Donors which displayed an increase in basophil activation and thus lower $\mathrm{C} 50$ values when cells were exposed to the AuNP-allergen conjugates 


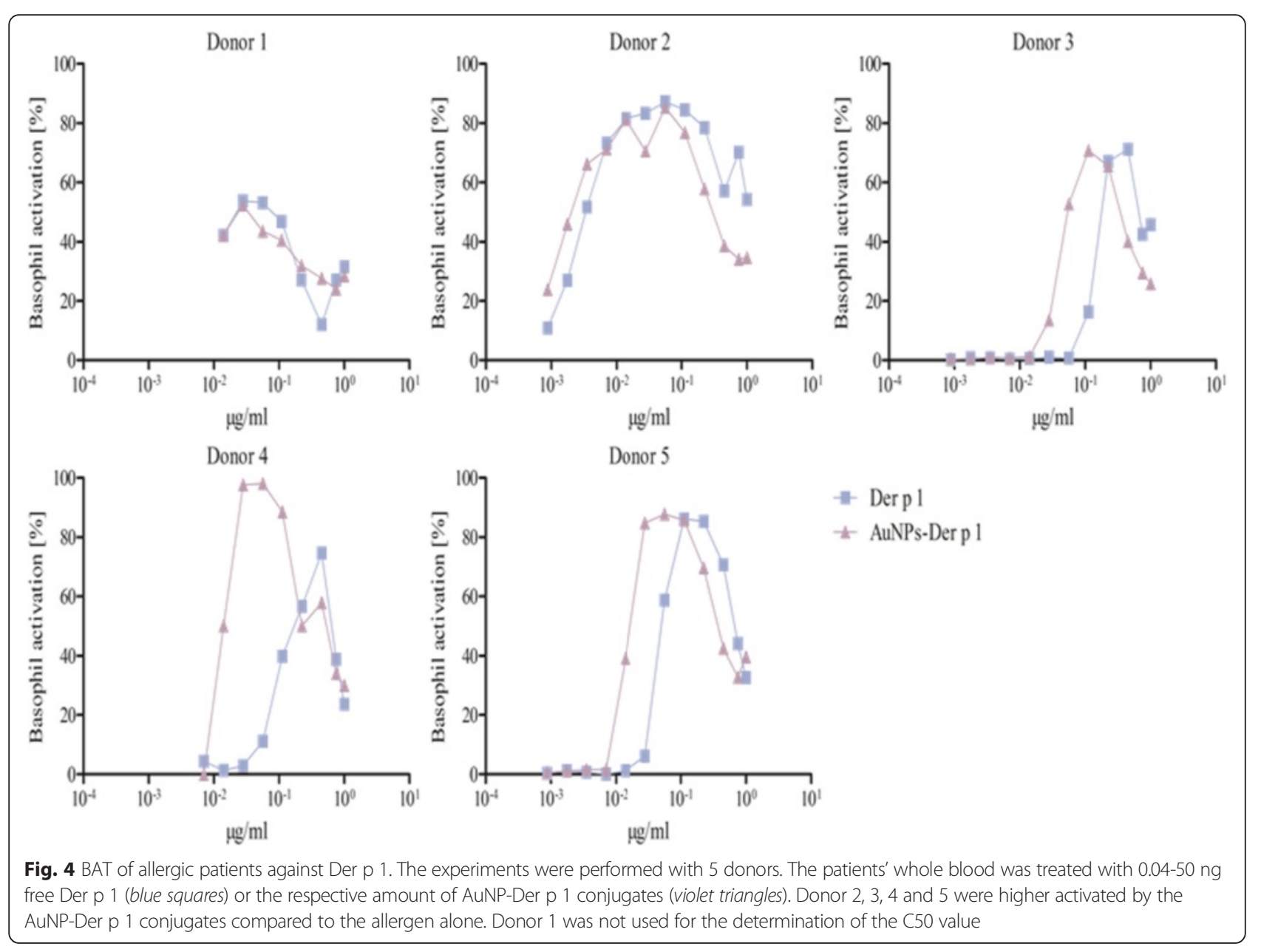

compared to free allergen. This was shown in three Bet v 1 donors, four Der p 1 donors, and one Phl p 5 donor (Figs. 3, 4, 5, Table 3). With our hypothesized uniform binding orientation, the conjugated allergens would align in the same direction enabling more IgE molecules to crosslink through an increased localized concentration of the bound allergen [75].

It was furthermore observed that four donors, two for Bet $\mathrm{v} 1$ (donors 3, 6), one for Der p 1 (donor 1), and one for Phl p 5 (donor 1), displayed a lower basophil sensitivity which manifested in a lower maximal activation response (Figs. 3, 4 and 5). Such examples have been described before and may be explained by either a lower total IgE concentration or less allergen-specific IgE bound to the basophils in those patients compared to the others [62].

\section{Using the enzymatic function for studying protein-} nanoparticle interactions - the protease activity of Der $p 1$ Since Der p 1 is known to be a cysteine protease [76], this intrinsic property was used to investigate the activity of free Der p 1 versus AuNP-Der p 1 conjugates in an enzyme activity assay and, secondly, their effect on cell monolayer tight junctions. For the enzyme activity assay, the effect of Der p 1 on t-Butyloxycarbonyl-L-glutaminylL-alanyl-L-arginine-4-methylcourmaryl-z-amide (BocGln-Ala-Arg-AMC) was investigated. Figure 6a displays the results obtained with $100 \mathrm{ng}$ and $50 \mathrm{ng}$ free Der p 1 compared to $30 \mathrm{ng}$ of conjugated Der p 1 . After $20 \mathrm{~min}$ the AMC release was 3-fold higher in case for AuNP-Der p 1 conjugates compared to 100 ng Der p 1 and 8-fold higher compared to $50 \mathrm{ng}$ Der $\mathrm{p} 1$. After $40 \mathrm{~min}$ the difference in AMC release was still 2-fold higher than for $100 \mathrm{ng}$ and 5 -fold higher than for 50 ng Der p 1 (data not shown). This observation could be due to the alignment of Der p 1 on the AuNP surface, which could lead to the observed higher enzymatic activity.

Additionally, the stability of conjugates, and enzyme activity, upon storage at $4{ }^{\circ} \mathrm{C}$ was investigated. Hence, the AuNP-Der p 1 conjugates were analyzed after one, two and three months of storage and compared to the fresh AuNP-Der $\mathrm{p} 1$ conjugates. In Fig. $6 \mathrm{~b}$ the difference in AMC release for AuNP-Der p 1 conjugates is shown; 


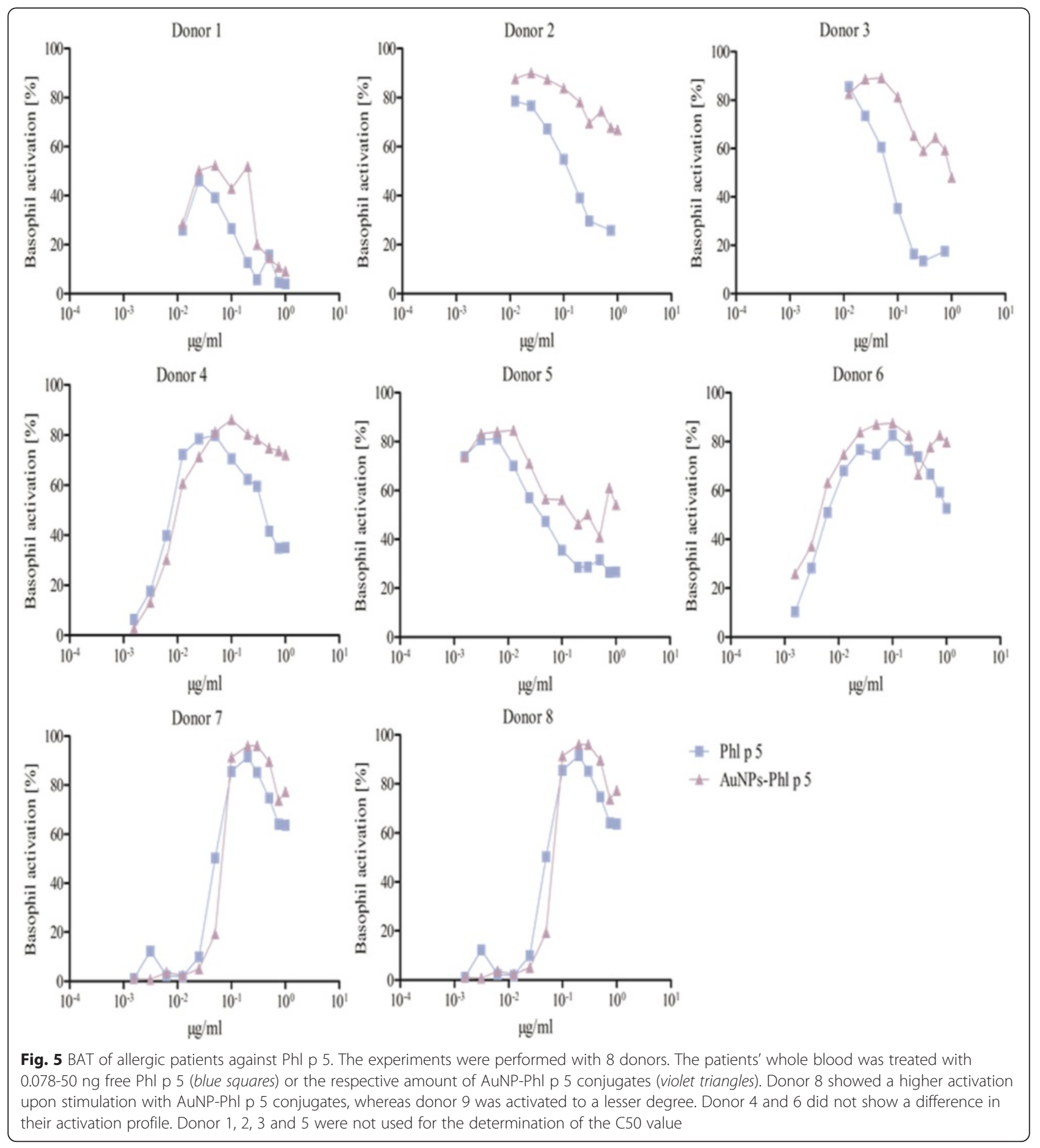

with a decrease in AMC release of 1.3-fold, 1.5-fold and 2.2-fold after one, two and three months, respectively, when compared to the fresh conjugates. These results gave an insight in the stability of the protein corona of Der $\mathrm{p} 1$ conjugated to AuNPs. Upon storage in $0.1 \mathrm{M}$ PBS without an excess of the protein, the proteins either slowly start to detach from the AuNPs surface or are subject to a limited degree of degradation.
The protease function of Der $\mathrm{p} 1$ has been reported to play a functional role in allergic sensitization, as the protease function may disrupt the epithelial barrier in the lung $[40,76]$. Consequently, such a marked increase in the enzymatic activity of AuNP-Der p 1 conjugates may have strong implications for allergic sensitization and lung pathophysiology upon uptake via inhalation. Therefore, permeability assays in A549 cells were carried out 
Table 3 Concentrations of half-maximal basophil activation (C50) of free allergen versus AuNP-allergen conjugates for all donors tested. In conjugates the given values refer to the amounts of coupled allergen. Donors displaying $X$ were tested but could not be statistically evaluated

\begin{tabular}{|c|c|c|c|c|c|c|}
\hline \multirow[b]{2}{*}{ Donor } & \multicolumn{6}{|c|}{$\mathrm{C} 50[\mathrm{ng} / \mathrm{ml}]$} \\
\hline & Bet $\vee 1$ & AuNP-Bet $\vee 1$ conjugates & Der p 1 & AuNP-Der $\mathrm{p} 1$ conjugates & $\mathrm{Phl}$ p 5 & AuNP-Phl p 5 conjugates \\
\hline 1 & $x$ & $x$ & $x$ & $x$ & $x$ & $x$ \\
\hline 2 & 178 & 1 & 4 & 2 & $x$ & $x$ \\
\hline 3 & 444 & 51 & 186 & 55 & $x$ & $x$ \\
\hline 4 & 52 & 13 & 27 & 1 & 16 & 19 \\
\hline 5 & 287 & 548 & 58 & 20 & $x$ & $x$ \\
\hline 6 & 78 & 107 & --- & --- & 1 & 1 \\
\hline 7 & 48 & 43 & --- & --- & 29 & 12 \\
\hline 8 & 2 & 2 & --- & --- & 65 & 77 \\
\hline 9 & 12 & 89 & --- & --- & --- & --- \\
\hline
\end{tabular}

to address whether in a more physiological model, compared to the enzyme activity assay, such a high impact of AuNPs-Der p 1 conjugates could be found. A549 are cancer cells derived from human type II alveolar epithelial cells, frequently used in investigating effects of inhaled ENMs, since they can form tight epithelia and reproduce other features of this cell type, for which primary cells cannot be obtained. Figure $6 \mathrm{c}$ displays the TEER measurements, as a measure of barrier function, of A549 cells grown on the membrane of an insert until forming a tight cell layer. The TEER values of the control cells on day 4 and 5 did not show significant further increases, indicating the formation of a tight monolayer at this time point, as previously described by Schlinkert et al. [77]. On day 4 the cells were treated for $24 \mathrm{~h}$ with free Der $\mathrm{p} 1$, AuNP-Der $\mathrm{p} 1$ conjugates, which were activated with $0.1 \mathrm{mM}$ DTT prior to the exposure, $2.5 \mathrm{M}$ EDTA as a positive control, DTT and plain AuNPs, to determine if any would alter the TEER values, or left untreated (Fig. 6d). The EDTA positive control, and more noteworthy, both allergen preparations, free Der $\mathrm{p} 1$ and AuNP-Der p 1 conjugates significantly decreased barrier function of the lung epithelial cells. Furthermore, when comparing free Der $\mathrm{p} 1$ to AuNP-Der $\mathrm{p} 1$ conjugates, AuNP-Der $\mathrm{p} 1$ conjugates had a higher impact on the integrity of the monolayer $(P<0.05)$. In contrast, neither $0.01 \mathrm{mM}$ DTT (used for activation of the protease function) nor the AuNPs alone had any effect on TEER values. The concentration of fluorescein permeating the tight layer was investigated using the same treatments as described above (Fig. 6e) [78]. These data were in line with the TEER measurements, with a significant increase in permeation when cells were exposed to AuNP-Der p 1 conjugates $(P<0.05)$ compared to the same amount of free Der $\mathrm{p} 1$. Both experiments verified the significant impact on the cell layer when cells were exposed to AuNP-Der p 1 conjugates, which also correlated well with the data observed in the enzymatic activity assay.

\section{Conclusions}

In this study we have shown the successful conjugation of three major outdoor and indoor allergens (Bet $\mathrm{v} 1$, Der p 1 and Phl p 5) as highly purified and wellcharacterized recombinant molecules to $50 \mathrm{~nm}$ AuNPs. The AuNP-allergen conjugates were characterized by TEM negative staining, DLS and hyperspectral imaging. All three characterization methods gave correlating results, namely that the allergens were firmly interacting with the AuNPs' surface. Indirect quantification by RPHPLC was performed allowing the determination of the allergen concentration on the AuNPs' surface. To visualize the interaction between the allergens and the AuNPs at the molecular level a 3D model was established based on crystal and NMR structural information, depicting the arrangement of the allergens on the AuNPs upon electrostatic interaction and the surface exposure of the known IgE-binding epitopes of the allergens. For providing experimental evidence for the generated models, the integrity and accessibility of IgE epitopes was determined by activation assays using human blood basophils derived from a panel of allergic patients. We observed a high donor-to-donor variability, depicting similar, higher or lower basophil responses to free allergen versus the respective amounts of AuNP-allergen conjugates. This led us to the conclusion that, (i) in case of similar results, the IgE epitopes of the allergens can be recognized equally well, (ii) in case of a lower basophil activation, some epitopes may become hidden, and the patients' specific IgE antibodies are not able to recognize other IgE epitopes present on the allergens' surface, and (iii) in the case of higher basophil activation, an alignment of the allergens on the AuNPs' surface takes place which optimally displays the IgE epitopes relevant for the respective patient. 

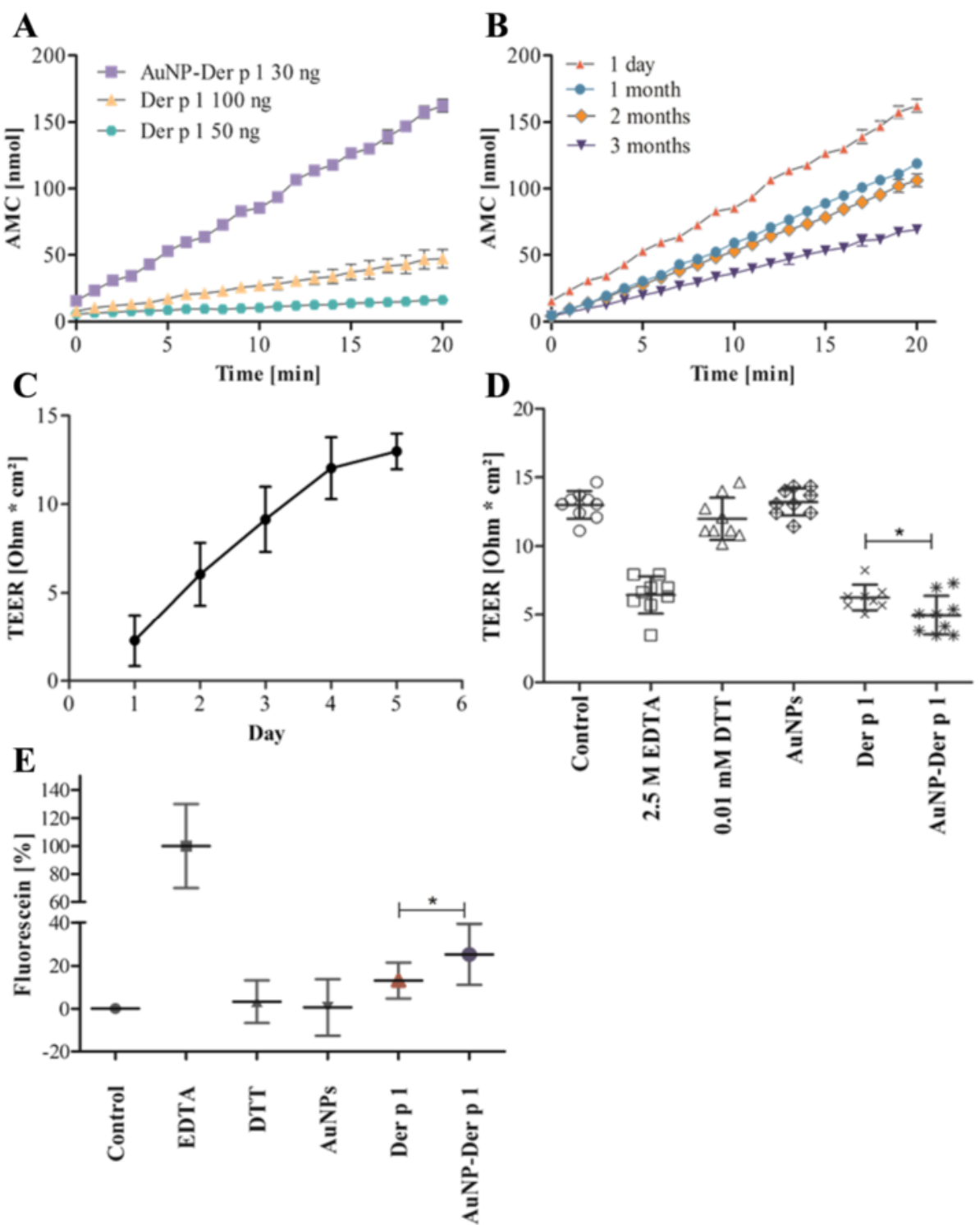

Fig. 6 Determination of protease activity of free Der $p 1$ versus AuNP-Der $p 1$ conjugates. a Enzymatic activity assay of 30 ng AuNP-Der p 1 conjugates compared to 50 and 100 ng free Der p 1. b Stability of conjugates addressed by enzymatic activity of 30 ng AuNP-Der p 1 conjugates upon storage at $4{ }^{\circ} \mathrm{C}$. In conjugates the given values refer to amount of coupled allergen. c TEER measurements of A549 cells to monitor the formation of a tight cell layer. d TEER measurements of A549 cells exposed to controls, free Der $p 1$ and AuNP-Der $p 1$ conjugates (*, $p<0.05$ ). e Permeation of Fluorescein through a tight monolayer of A549 cells exposed to controls, free Der $p 1$ and AuNP-Der $p 1$ conjugates (*, $p<0.05)$

This would facilitate a more effective IgE receptor crosslinking on the basophils due to a higher localized concentration of allergens on the AuNPs compared to the free allergen.

AuNP-Der p 1 conjugates were the only AuNP-allergen conjugates affected by replacement of plasma proteins, when determining the "hardness" of the protein corona formed via Western blots as control experiments for the AuNP-allergen conjugate incubation in plasma during BAT (Additional File 1: Supplementary material and Additional File 2: Figure S1). We, furthermore, determined that the enzymatic activity of Der p 1 upon binding to AuNPs was markedly enhanced in a cell free assay, and accordingly, the conjugates reduced the integrity of a tight cell monolayer when compared to free Der p 1. Release of Der $p 1$ from AuNPs was not fast enough, or to a high enough level, to abolish an allergy-promoting effect as shown by increased basophil activation. Studies with other allergens are needed to show how frequent such effects are for allergens in general.

In summary, this study presents that conjugation of allergens to ENMs can modulate the allergic response. Yet, due to allergic donor variability, this effect was not consistently observed. Furthermore the enzymatic activity of the protease Der p 1 was increased when conjugated to ENMs. 


\section{Additional files}

Additional file 1 Figure S1. Supplementary material. Control for allergen corona replacement during basophil activation assays. (DOCX 573 kb)

Additional file $\mathbf{2}$ Determination of conjugated allergen after the incubation in human plasma performed by Coomassie-stained SDS-PAGE (A-C) and Western blots (D-F). (TIF $526 \mathrm{~kb}$ )

\begin{abstract}
Abbreviations
ACN: acetonitrile; AuNPs: gold nanoparticles; BAT: basophil activation test; Boc-Gln-Ala-Arg-AMC: t-Butyloxycarbonyl-L-glutaminyl-L-alanyl-L-arginine-4methylcourmaryl-z-amide; CCL: CC-chemokine ligand; CCR: CC-chemokine receptor; CD63: cluster of differentiation 63; DCs: dendritic cells; DEPs: diesel exhaust particles; DLS: dynamic light scattering; DTT: dithiothreitol; EDTA: ethylene diamine tetraacetic acid; ENMs: engineered nanomaterials: FCS: fetal calf serum; FceRl: high affinity receptor for lgE; HRP: horse radish peroxidase; Ig: immunoglobulin; IL: interleukin; mAb: monoclonal antibody; NMR: nuclear magnetic resonance; PBS: phosphate-buffered saline; Pdl: polydispersity index; ROI: region of interest; RP-HPLC: reversed phase-high performance liquid chromatography; SAM: spectral angle mapper; SD: standard deviation; SDS: sodium dodecyl sulfate; SDS-PAGE: sodium dodecyl sulfate polyacrylamide gel; SSC: side scatter; TBS: tris-buffered saline; TEER: transepithelial electrical resistance; TEM: transmission electron microscopy; TFA: trifluoroacetic acid; $T_{H} 2$ : $T$ helper cell 2 ; TSLP: thymic stromal lymphopoietin.
\end{abstract}

\section{Competing interests}

The authors declare that they have no competing interests.

\section{Authors' contributions}

IRP, AA, MW performed experimental work; IRP, MB, MW, MH evaluated data; TH provided material; ULM, AD provided experimental/instrumental infrastructure and know how; IRP, MB, JHH, MH, AD conceived the study; IRP, MB, MW, MH, AD wrote and edited the manuscript; AD provided funding. All authors read and approved the final manuscript.

\section{Acknowledgements}

The research leading to these results has received funding from the European Community's Seventh Framework Programme (FP7/2007-2013) under grant agreement No: 263147 (NanoValid - Development of reference methods for hazard identification, risk assessment and LCA of engineered nanomaterials). We thank Sabine Flicker, Susanne Vrtala and Rudolf Valenta from the center for pathophysiology, infectiology and immunology at the medical university of Vienna for providing the allergen-specific lgG antibodies; Samuel M. Lawrence, Leslie Krauss from CytoViva Inc. and Hoffmann Goetz from Schaefer Technology GmbH for conducting the hyperspectral images and analysis of AuNPs and AuNP-allergen conjugates, and Quentin Peacock from QxDesign for preparing the abstract graphic.

\section{Author details}

'Department of Molecular Biology, Division of Allergy and Immunology, University of Salzburg, Hellbrunnerstr, 34, 5020 Salzburg, Austria. ${ }^{2}$ Department of Cell Biology, Division of Plant Physiology, University of Salzburg, Salzburg, Austria. ${ }^{3}$ Department of Dermatology, Paracelsus Medical University, Salzburg, Austria. ${ }^{4}$ Department of Molecular Biology, Division of Structural Biology and Bioinformatics, University of Salzburg, Salzburg, Austria. ${ }^{5}$ Heriot-Watt University, Edinburgh, UK.

Received: 28 July 2015 Accepted: 4 January 2016

Published online: 16 January 2016

\section{References}

1. Oberdorster G. Safety assessment for nanotechnology and nanomedicine: concepts of nanotoxicology. J Intern Med. 2010;267(1):89-105. doi:10.1111/j.1365-2796.2009.02187.x

2. Oberdörster G, Stone $V$, Donaldson $K$. Toxicology of nanoparticles: A historica perspective. Nanotoxicology. 2007;1(1):2-25. doi:10.1080/17435390701314761.

3. Seaton A, Tran L, Aitken R. Nanoparticles, human health hazard and regulation. J R Soc Interface. 2010;7 Suppl 1:S119-29. doi:10.1098/rsif.2009.0252.focus.
4. Mahon E, Salvati A, Baldelli Bombelli F, Lynch I, Dawson KA. Designing the nanoparticle-biomolecule interface for "targeting and therapeutic delivery". J Control Release. 2012;161(2):164-74. doi:10.1016/j.jconrel.2012.04.009.

5. Borm PJ, Robbins D, Haubold S, Kuhlbusch T, Fissan H, Donaldson K, et al. The potential risks of nanomaterials: a review carried out for ECETOC. Part Fibre Toxicol. 2006;3:11. doi:10.1186/1743-8977-3-11.

6. Monopoli MP, Walczyk D, Campbell A, Elia G, Lynch I, Bombelli FB, et al. Physical-chemical aspects of protein corona: relevance to in vitro and in vivo biological impacts of nanoparticles. J Am Chem Soc. 2011;133(8):2525-34. doi:10.1021/ja107583h

7. Saptarshi SR, Duschl A, Lopata AL. Interaction of nanoparticles with proteins: relation to bio-reactivity of the nanoparticle. J Nanobiotechnol. 2013;11:26. doi:10.1186/1477-3155-11-26.

8. Nel AE, Madler L, Velegol D, Xia T, Hoek EM, Somasundaran P, et al. Understanding biophysicochemical interactions at the nano-bio interface. Nat Mater. 2009;8(7):543-57. doi:10.1038/nmat2442.

9. Kreyling WG, Semmler-Behnke M, Seitz J, Scymczak W, Wenk A, Mayer P, et al. Size dependence of the translocation of inhaled iridium and carbon nanoparticle aggregates from the lung of rats to the blood and secondary target organs. Inhal Toxicol. 2009;21 Suppl 1:55-60. doi:10.1080/ 08958370902942517.

10. Nemmar A, Hoet PH, Vanquickenborne B, Dinsdale D, Thomeer M, Hoylaerts MF, et al. Passage of inhaled particles into the blood circulation in humans. Circulation. 2002;105(4):411-4.

11. Weinberg EG. The Wao White Book on allergy 2011-2012. Curr Allergy Clin Im. 2011;24(3):156-7.

12. Hammad $H$, Lambrecht BN. Dendritic cells and epithelial cells: linking innate and adaptive immunity in asthma. Nat Rev Immunol. 2008;8(3):193-204. doi:10.1038/nri2275

13. Zhou B, Comeau MR, De Smedt T, Liggitt HD, Dahl ME, Lewis DB, et al. Thymic stromal lymphopoietin as a key initiator of allergic airway inflammation in mice. Nat Immunol. 2005;6(10):1047-53. doi:10.1038/ni1247

14. Ziegler SF, Artis D. Sensing the outside world: TSLP regulates barrier immunity. Nat Immunol. 2010;11(4):289-93. doi:10.1038/ni.1852.

15. Dullaers M, De Bruyne R, Ramadani F, Gould HJ, Gevaert P, Lambrecht BN. The who, where, and when of IgE in allergic airway disease. J Allergy Clin Immunol. 2012;129(3):635-45. doi:10.1016/j.jaci.2011.10.029.

16. Galli SJ, Tsai M, Piliponsky AM. The development of allergic inflammation. Nature. 2008:454(7203):445-54. doi:10.1038/nature07204.

17. Galli SJ, Tsai M. IgE and mast cells in allergic disease. Nat Med. 2012;18(5):693-704 doi:10.1038/nm.2755

18. He SH, Zhang HY, Zeng XN, Chen D, Yang PC. Mast cells and basophils are essential for allergies: mechanisms of allergic inflammation and a proposed procedure for diagnosis. Acta Pharmacol Sin. 2013;34(10):1270-83. doi:10.1038/ aps.2013.88

19. Holgate ST. The epidemic of allergy and asthma. Nature. 1999;402(6760 Suppl):B2-4

20. Skoner DP. Allergic rhinitis: definition, epidemiology, pathophysiology, detection, and diagnosis. J Allergy Clin Immunol. 2001;108(1 Suppl):S2-8.

21. D'Amato G, Cecchi L, Bonini S, Nunes C, Annesi-Maesano I, Behrendt H, et al. Allergenic pollen and pollen allergy in Europe. Allergy. 2007;62(9):976-90. doi:10.1111/j.1398-9995.2007.01393x

22. Calderon MA, Linneberg A, Kleine-Tebbe J, De Blay F, Hernandez Fernandez de Rojas D, Virchow JC, et al. Respiratory allergy caused by house dust mites: What do we really know? J Allergy Clin Immunol. 2014. doi:10.1016/j. jaci.2014.10.012.

23. Zock JP, Heinrich J, Jarvis D, Verlato G, Norback D, Plana E, et al. Distribution and determinants of house dust mite allergens in Europe: the European Community Respiratory Health Survey II. J Allergy Clin Immunol. 2006;1 18(3): 682-90. doi:10.1016/j.jaci.2006.04.060.

24. Knox RB, Suphioglu C, Taylor P, Desai R, Watson HC, Peng JL, et al. Major grass pollen allergen Lol p 1 binds to diesel exhaust particles: implications for asthma and air pollution. Clin Exp Allergy. 1997:27(3):246-51.

25. Tsien A, Diaz-Sanchez D, Ma J, Saxon A. The organic component of diesel exhaust particles and phenanthrene, a major polyaromatic hydrocarbon constituent, enhances lgE production by IgE-secreting EBV-transformed human B cells in vitro. Toxicol Appl Pharmacol. 1997;142(2):256-63. doi:10.1006/taap. 1996.8063

26. Diaz-Sanchez D, Tsien A, Fleming J, Saxon A. Combined diesel exhaust particulate and ragweed allergen challenge markedly enhances human in 
vivo nasal ragweed-specific lgE and skews cytokine production to a T helper cell 2-type pattern. J Immunol. 1997;158(5):2406-13.

27. Takano H, Yanagisawa R, Ichinose T, Sadakane K, Yoshino S, Yoshikawa T, et al. Diesel exhaust particles enhance lung injury related to bacterial endotoxin through expression of proinflammatory cytokines, chemokines, and intercellular adhesion molecule-1. Am J Respir Crit Care Med. 2002;165(9):1329-35. doi:10. $1164 / \mathrm{rccm} .2108122$

28. Gomez S, Gamazo C, San Roman B, Grau A, Espuelas S, Ferrer M, et al. A novel nanoparticulate adjuvant for immunotherapy with Lolium perenne. J Immunol Methods. 2009;348(1-2):1-8. http://dx.doi.org/10.1016/j.jim.2009.06.005.

29. Licciardi M, Montana G, Bondi ML, Bonura A, Scialabba C, Melis M, et al. An allergen-polymeric nanoaggregate as a new tool for allergy vaccination. Int J Pharm. 2014;465(1-2):275-83. http://dx.doi.org/10.1016/j.jpharm.2014.01.031.

30. Nouri HR, Varasteh A, Jaafari MR, Davies JM, Sankian M. Induction of a Th1 immune response and suppression of IgE via immunotherapy with a recombinant hybrid molecule encapsulated in liposome-protamineDNA nanoparticles in a model of experimental allergy. Immunol Res. 2015;62(3):280-91. doi:10.1007/s12026-015-8659-8.

31. Pali-Scholl I, Szollosi H, Starkl P, Scheicher B, Stremnitzer C, Hofmeister A, et al. Protamine nanoparticles with CpG-oligodeoxynucleotide prevent an allergen-induced Th2-response in BALB/c mice. Eur J Pharm Biopharm. 2013;85(3, Part A):656-64. http://dx.doi.org/10.1016/j.ejpb.2013.03.003.

32. Salem AK. A promising CpG adjuvant-loaded nanoparticle-based vaccine for treatment of dust mite allergies. Immunotherapy. 2014;6(11):1161-3. doi:10.2217/imt.14.97.

33. Chuang HC, Hsiao TC, Wu CK, Chang HH, Lee CH, Chang CC, et al. Allergenicity and toxicology of inhaled silver nanoparticles in allergenprovocation mice models. Int J Nanomedicine. 2013;8:4495-506. doi:10. 2147/IJN.S52239.

34. Brandenberger C, Rowley NL, Jackson-Humbles DN, Zhang Q, Bramble LA, Lewandowski RP, et al. Engineered silica nanoparticles act as adjuvants to enhance allergic airway disease in mice. Part Fibre Toxicol. 2013;10:26. doi: 10.1186/1743-8977-10-26.

35. Ilves M, Palomaki J, Vippola M, Lehto M, Savolainen K, Savinko T, et al. Topically applied ZnO nanoparticles suppress allergen induced skin inflammation but induce vigorous IgE production in the atopic dermatitis mouse model. Part Fibre Toxicol. 2014;11:38. doi:10.1186/s12989-014-0038-4.

36. Jonasson S, Gustafsson A, Koch B, Bucht A. Inhalation exposure of nanoscaled titanium dioxide (TiO2) particles alters the inflammatory responses in asthmatic mice. Inhal Toxicol. 2013;25(4):179-91.

37. Lefebvre DE, Pearce B, Fine JH, Chomyshyn E, Ross N, Halappanavar S, et al. In vitro enhancement of mouse T Helper 2 cell sensitization to ovalbumin allergen by carbon black nanoparticles. Toxicol Sci. 2014;138(2):322-32. doi: 10.1093/toxsci/kfu010.

38. Nygaard UC, Samuelsen M, Marioara CD, Lovik M. Carbon nanofibers have IgE adjuvant capacity but are less potent than nanotubes in promoting allergic airway responses. BioMed Res Int. 2013;2013:476010. doi:10.1155/2013/ 476010.

39. Su CL, Chen TT, Chang CC, Chuang KJ, Wu CK, Liu WT, et al. Comparative proteomics of inhaled silver nanoparticles in healthy and allergen provoked mice. Int J Nanomedicine. 2013:8:2783-99. doi:10.2147/IJN.S46997.

40. Wan H, Winton HL, Soeller C, Tovey ER, Gruenert DC, Thompson PJ, et al. Der $p 1$ facilitates transepithelial allergen delivery by disruption of tight junctions. J Clin Invest. 1999;104(1):123-33. doi:10.1172/JCl5844.

41. Ackaert C, Kofler S, Horejs-Hoeck J, Zulehner N, Asam C, von Grafenstein S, et al. The impact of nitration on the structure and immunogenicity of the major birch pollen allergen Bet v 1.0101. PLoS One. 2014;9(8):e104520. doi: 10.1371/journal.pone.0104520.

42. Cromwell O, Suck R, Kahlert $H$, Nandy A, Weber B, Fiebig H. Transition of recombinant allergens from bench to clinical application. Methods. 2004; 32(3):300-12. doi:10.1016/j.ymeth.2003.08.009.

43. Himly M, Nony E, Chabre H, Van Overtvelt L, Neubauer A, van Ree R, et al. Standardization of allergen products: 1. Detailed characterization of GMPproduced recombinant Bet $\vee 1.0101$ as biological reference preparation. Allergy. 2009;64(7):1038-45. doi:10.1111/j.1398-9995.2009.01957.x.

44. Pettersen EF, Goddard TD, Huang CC, Couch GS, Greenblatt DM, Meng EC, et al. UCSF Chimera-A visualization system for exploratory research and analysis. J Comput Chem. 2004;25(13):1605-12. doi:10. 1002/jcc.20084.

45. Chruszcz M, Chapman MD, Vailes LD, Stura EA, Saint-Remy JM, Minor W, et al. Crystal structures of mite allergens Der $f 1$ and Der $p 1$ reveal differences in surface-exposed residues that may influence antibody binding. J Mol Biol. 2009;386(2):520-30. doi:10.1016/j.jmb.2008.12.049.

46. Kofler S, Asam C, Eckhard U, Wallner M, Ferreira F, Brandstetter $H$. Crystallographically mapped ligand binding differs in high and low lgE binding isoforms of birch pollen allergen bet v 1. J Mol Biol. 2012;422(1):109-23. doi:10. 1016/j.jmb.2012.05.016.

47. Dolinsky TJ, Czodrowski P, Li H, Nielsen JE, Jensen JH, Klebe G, et al. PDB2PQR: expanding and upgrading automated preparation of biomolecular structures for molecular simulations. Nucleic Acids Res. 2007 35 suppl 2:W522-5. doi:10.1093/nar/gkm276.

48. Dolinsky TJ, Nielsen JE, McCammon JA, Baker NA. PDB2PQR: an automated pipeline for the setup of Poisson-Boltzmann electrostatics calculations. Nucleic Acids Res. 2004;32(Web Server issue):W665-7. doi:10.1093/nar/gkh381.

49. Sitkoff D, Sharp KA, Honig B. Accurate calculation of hydration free energies using macroscopic solvent models. J Phys Chem. 1994;98(7):1978-88. doi:10.1021/j100058a043.

50. Baker NA, Sept D, Joseph S, Holst MJ, McCammon JA. Electrostatics of nanosystems: Application to microtubules and the ribosome. Proc Natl Acad Sci U S A. 2001;98(18):10037-41. doi:10.1073/pnas.181342398.

51. Brar SK, Verma M. Measurement of nanoparticles by light-scattering techniques. TrAC Trends Anal Chem. 2011;30(1):4-17. doi:10.1016/j.trac.2010.08.008.

52. de Halleux S, Stura E, VanderElst L, Carlier V, Jacquemin M, Saint-Remy JM. Three-dimensional structure and IgE-binding properties of mature fully active Der p 1, a clinically relevant major allergen. J Allergy Clin Immunol. 2006;117(3): 571-6. doi:10.1016/j.jaci.2005.11.032.

53. Dell'Orco D, Lundqvist M, Oslakovic C, Cedervall T, Linse S. Modeling the time evolution of the nanoparticle-protein corona in a body fluid. PLoS One. 2010;5(6):e10949. doi:10.1371/journal.pone.0010949.

54. Arbos P, Arangoa MA, Campanero MA, Irache JM. Quantification of the bioadhesive properties of protein-coated PVM/MA nanoparticles. Int J Pharm. 2002;242(1-2):129-36.

55. Brancolini G, Kokh DB, Calzolai L, Wade RC, Corni S. Docking of ubiquitin to gold nanoparticles. ACS Nano. 2012;6(11):9863-78. doi:10.1021/nn303444b.

56. Calzolai L, Franchini F, Gilliland D, Rossi F. Protein-nanoparticle interaction: identification of the ubiquitin-gold nanoparticle interaction site. Nano Lett. 2010;10(8):3101-5. doi:10.1021/nl101746v.

57. Brancolini G, Corazza A, Vuano M, Fogolari F, Mimmi MC, Bellotti V, et al. Probing the influence of citrate-capped gold nanoparticles on an amyloidogenic protein. ACS Nano. 2015;9(3):2600-13. doi:10.1021/nn506161j.

58. Brewer SH, Glomm WR, Johnson MC, Knag MK, Franzen S. Probing BSA binding to citrate-coated gold nanoparticles and surfaces. Langmuir. 2005; 21(20):9303-7. doi:10.1021/la050588t.

59. Hoffmann HJ, Santos AF, Mayorga C, Nopp A, Eberlein B, Ferrer M, et al. The clinical utility of basophil activation testing in diagnosis and monitoring of allergic disease. Allergy. 2015;70(11):1393-405. doi:10.1111/all.12698.

60. MacGlashan Jr DW. Basophil activation testing. J Allergy Clin Immunol. 2013;132(4):777-87. doi:10.1016/j.jaci.2013.06.038.

61. Siracusa MC, Kim BS, Spergel JM, Artis D. Basophils and allergic inflammation. J Allergy Clin Immunol. 2013;132(4):789-801. doi:10.1016/j.jaci.2013.07.046. quiz 788.

62. Christensen LH, Holm J, Lund G, Riise E, Lund K. Several distinct properties of the IgE repertoire determine effector cell degranulation in response to allergen challenge. J Allergy Clin Immunol. 2008;122(2):298-304.

63. McGowan EC, Saini S. Update on the performance and application of basophil activation tests. Curr Allergy Asthma Rep. 2013;13(1):101-9. doi:10.1007/s11882-012-0324-x

64. Stone KD, Prussin C, Metcalfe DD. IgE, mast cells, basophils, and eosinophils. J Allergy Clin Immunol. 2010;125(2):S73-80.

65. Gepp B, Lengger N, Bublin M, Hemmer W, Breiteneder H, Radauer C. Chimeras of Bet $\vee 1$ and Api g 1 reveal heterogeneous lgE responses in patients with birch pollen allergy. J Allergy Clin Immunol. 2014;134(1):18894. doi:10.1016/j.jaci.2013.12.1073.

66. Knol EF. Requirements for effective lgE cross-linking on mast cells and basophils. Mol Nutr Food Res. 2006;50(7):620-4.

67. Chapman MD, Heymann PW, Platts-Mills TA. Epitope mapping of two major inhalant allergens, Der $\mathrm{p} \mathrm{I}$ and Der $\mathrm{fl}$, from mites of the genus Dermatophagoides. J Immunol. 1987;139(5):1479-84.

68. Dai YC, Chuang WJ, Chua KY, Shieh CC, Wang JY. Epitope mapping and structural analysis of the anti-Der p 1 monoclonal antibody: insight into therapeutic potential. J Mol Med. 2011;89(7):701-12. doi:10.1007/s00109011-0744-4 
69. Focke-Tejkl M, Campana R, Reininger R, Lupinek C, Blatt K, Valent P, et al. Dissection of the lgE and T-cell recognition of the major group 5 grass pollen allergen Phl p 5. J Allergy Clin Immunol. 2014;133(3):836-45. doi:10. 1016/j.jaci.2013.08.038. e11.

70. Levin M, Davies AM, Liljekvist M, Carlsson F, Gould HJ, Sutton BJ, et al. Human lgE against the major allergen Bet $\mathrm{v} 1$-defining an epitope with limited crossreactivity between different PR-10 family proteins. Clin Exp Allergy. 2014;44(2): 288-99. doi:10.1111/cea.12230.

71. Szalai K, Fuhrmann J, Pavkov T, Scheidl M, Wallmann J, Bramswig KH, et al. Mimotopes identify conformational B-cell epitopes on the two major house dust mite allergens Der p 1 and Der p 2. Mol Immunol. 2008:45(5):1308-17. doi:10.1016/j.molimm.2007.09.012.

72. Takai T, Kato T, Yasueda H, Okumura K, Ogawa H. Analysis of the structure and allergenicity of recombinant pro- and mature Der $\mathrm{p} 1$ and Der $\mathrm{f}$ 1: major conformational IgE epitopes blocked by prodomains. J Allergy Clin Immunol. 2005;115(3):555-63. doi:10.1016/j.jaci.2004.11.024.

73. Furmonaviciene R, Tighe PJ, Clark MR, Sewell HF, Shakib F. The use of phagepeptide libraries to define the epitope specificity of a mouse monoclonal antiDer $p 1$ antibody representative of a major component of the human immunoglobulin E anti-Der p 1 response. Clin Exp Allergy. 1999;29(11): 1563-71.

74. Lynch I, Salvati A, Dawson KA. Protein-nanoparticle interactions: What does the cell see? Nat Nanotechnol. 2009;4(9):546-7. doi:10.1038/nnano.2009.248.

75. Monopoli MP, Aberg C, Salvati A, Dawson KA. Biomolecular coronas provide the biological identity of nanosized materials. Nat Nanotechnol. 2012;7(12): 779-86. doi:10.1038/nnano.2012.207.

76. Bessot J, Pauli G. Mite allergens: an overview. Eur Ann Allergy Clin Immunol. 2011;43(5):141.

77. Schlinkert P, Casals E, Boyles M, Tischler U, Hornig E, Tran N, et al. The oxidative potential of differently charged silver and gold nanoparticles on three human lung epithelial cell types. J Nanobiotechnol. 2015;13(1):1. doi: 10.1186/s12951-014-0062-4.

78. El-Sayed M, Ginski M, Rhodes C, et al. Transepithelial transport of poly(amidoamine) dendrimers across Caco-2 cell monolayers. J Control Release. 2002:81(3):355-65.

\section{Submit your next manuscript to BioMed Central and we will help you at every step:}

- We accept pre-submission inquiries

- Our selector tool helps you to find the most relevant journal

- We provide round the clock customer support

- Convenient online submission

- Thorough peer review

- Inclusion in PubMed and all major indexing services

- Maximum visibility for your research

Submit your manuscript at www.biomedcentral.com/submit
C Biomed Central 